Article

\title{
Addressing on Mechanism of Different Types of ENSO and Related Teleconnections and Solar Influence
}

\author{
Indrani Roy \\ College of Engineering, Mathematics and Physical Sciences, University of Exeter, \\ Laver Building, Streatham Campus, North Park Road, Exeter EX4 4QE, UK; \\ indrani_r@hotmail.com
}

\begin{abstract}
A flow-chart is presented depicting atmosphere-ocean coupling, which is initiated by decadal solar variability. Possible mechanisms for Canonic ENSO, Modoki ENSO and Canonic-Modoki ENSO are proposed and their relevance to the decadal variation of Hadley, Walker circulation and mid-latitude jets are discussed. We also show subsequent teleconnections by ENSO for eg., on ISM with a special emphasis on later two decades of the last century. As there is a disruption of the usual ENSO-ISM teleconnection, we discussed on possible mechanism. The role of volcanos and the change in sun-NAO connection were discussed. The regional Hadley circulation, via NAO in the northern hemisphere and Indian Ocean Dipole in the southern hemisphere, may have a role in the change of ISM behaviour. Such flow-chart helps to improve our understanding of various types of ENSO in both temporal as well as spatial scale. It subsequently can benefit the modelling community by improved representation of ENSO in models.
\end{abstract}

Keywords: solar cyclic variability; Canonical and Modoki ENSO; Indian summer monsoon 


\section{Introduction.}

The El Nino Southern Oscillation (ENSO) is one of the most important tropospheric variability that influences most parts of the globe through teleconnection. It has significant impacts on seasonal precipitation in several places around the world. Different types of ENSO, based on spatial pattern of Tropical Pacific SST, one dominated by variability around East Pacific (EP), known as EP type or Canonical ENSO and the other dominated by variability around Central Pacific (CP), known as CP type or Modoki ENSO, have been discussed in several studies (Trenberth et al., 2002; Larkin and Harrison, 2005; Ashok et al., 2007; Hill et al., 2009; Kug et al. 2009).

Studies suggest there are differences in global and local influences between ENSO Modoki and Canonical ENSO (Global: Ashok et al., 2007; Weng et al., 2007; Pacific Rim: Weng et al., 2009; South China Sea: Chang et al., 2008; Australia: Brown et al., 2009; Cai and Cowan, 2009; Taschetto and England, 2009; India: Roy and Tedeschi, 2016; Roy et al, 2016). Such studies indicate the importance of understanding the underlying mechanism of these two types of ENSO to improve prediction skill.

Kao and $\mathrm{Yu}$ (2009) in a review compared these two types of ENSO, regarding of their structure and evolution. They showed EP ENSO is mainly regulated by thermocline shifting, though for CP ENSO, atmospheric forcing plays the dominant role. Thermocline uplifting (deepening down) for $L N(E N)$ is related to oceanic Rossby/ Kelvin wave movement and hence the signature of phase reversal is identified in EP type of ENSO, but CP type occurs more as events or epochs than as a cycle. Yu and Kao (2007) indicated different mechanism for two forms of ENSO. The CP ENSO is phase locked with season with its phase transition (onset, barrier, etc.) happens in spring; while for EP ENSO, though it is mainly regulated by the thermocline shifting, the phase shift and barrier changes decade to decade. Considering different onset times of these two types of ENSO, Kao and Yu (2009) suggested it could be 
caused by the timing of the mechanisms that trigger those ENSO events. As mentioned, for EP ENSO thermocline shifting is known to be the primary driver (Ashok, 2007; Kao and Yu, 2009), but for CP ENSO, there are extratropical connections. Two mechanisms for such extratropical connections are proposed, Equatorial Ocean Advection Theory (Kug et al. 2009) and Extra-tropical Forcing Theory (Kao and Yu 2009, Yu et al. 2010, Yu and Kim 2011). Based on the first theory, anomalous SST is grown by the zonal ocean advection along the equatorial Pacific, while using the second, it is first excited by extra-tropical forcing and then developed by the tropical ocean advection. Various studies proposed about a decadal connection of ENSO (Henyi and Deng, (2011), McPhaden et al. (2011), Meehl et al. (2008, 2009), Roy, I (2014)). An underlying quasi-decadal variability in the interannual ENSO is detected in several studies (White et al., 2008; Zhang et al., 1997; Zhao et al., 2003; Chen et al 2004).

The Sun provides the fundamental source of energy for the climate system, but the level of scientific understanding relating to its influences on a climate of the earth is still low. Though regarding terms of energy output, there is only a $0.1 \%$ change from maximum to minimum years of the 11-year cycle (Lean and Rind, 2001), too negligible to influence climate but studies identified the significant regional impact seasonally which also depend on overall period chosen. Decadal signature of solar variability changes is also detected in various atmospheric and oceanic fields. In terms of atmospheric fields it is detected in tropospheric circulations (Hadley Circulation: Haigh et al. (1999, 1996, 2005); Walker Circulation: Meehl et al. (2008, 2009)); Polar Vortex (Kodera, 2002); Midlatitude Jet (Haigh, 2005; Bronnimann 2006) and Intertropical Convergence Zone (ITCZ) (Lee, et al. 2009). Decadal signature is also distinguished in various oceanic parameters (thermocline: Zhang et al., (2006); North Pacific gyre circulation: Lorenzo et al. (2010) and shallow Meridional Overturning Circulation (MOC) in Pacific: Zhang et al. (2006)).

The ENSO through teleconnection can influence seasonal precipitation in several places around the world, among which Indian summer monsoon (ISM) is an important one. Studies 
have shown that the EI Niño Southern Oscillation (ENSO) strongly modulates the ISM (e.g. Kripalani RH and A Kulkarni 1997; Maity and Kumar, 2006). Parts of CNE region of India around ITCZ, where the coupling mechanism of atmosphere and ocean via ENSO through the Walker circulation could be communicated strongly was also captured by CMIP5 models and observation (Roy et al (2016)). However, monsoon precipitation and ENSO show a weaker correlation during last few decades of the twentieth century, with the Indian monsoon occurring with normal levels of rainfall despite the occurrence of El Niños (Kumar et al, 1999; Ashok et al., 2001). Ashok et al. (2001) showed that Indian Ocean Dipole (IOD) and ENSO have complementarily affected the ISM during a similar period. They revealed that when the correlation between ENSO and ISM is little, the relationship between IOD and ISM high and vice versa. Roy and Collins (2015) using observational data of sea level pressure (SLP) showed that the Southern Oscillation (SO) pattern as captured in the ENSO indicates major changes around Australia in the later half of last century. Interestingly, Australia (Darwin), one lobe of SO is also coincidentally one end of IOD. ISM is also strongly modulated by the North Atlantic Oscillation (NAO) (Liu \& Yanai, 2001). The relationship between the temperature of West Eurasia and ISM is stronger, over the same period the relationship between the ENSO and ISM has weakened (Chang et al., 2001). According to them, as the ENSO ISM relationship has weakened, the possibility for the NAO to influence the ISM through the above mechanism has increased.

The regional monsoon-ENSO relationship is shown having common changing points around the 1970s. There was an enhancement of the relations for the western North Pacific, North American, Northern African, and South American summer monsoons, with a recovery in the late 1990s. But for the Indian summer monsoon, it weakened over the same period (Yim et al. 2013). Huang, P. et al. (2013) also recently discussed a changing pattern of monsoon in global warming situation. The observation suggests decreasing trend in precipitation around India (Goswami (2006), Ramanathan et al. 2005, Chung et al. 2006) contradicting the proposed hypothesis based on thermodynamic scaling (Held and Soden (2006)). The direction of 
anomalous change in circulation, both the Hadley and Walker circulation and their relative strength around the Indian subcontinent, mainly in the Central North East India, under climate change scenario, needs additional attention (Bollasina, 2011). Observation indicates that the nature of ENSO also changed in last few decades. ENSO Modoki became more frequent and persistent since the 1970s (Ashok and Yamagata, (2009); Yeh et al. (2009)). Research suggests that the increase of CP ENSO during latter decades of last century could also be due to parts of decadal nature variability (McPhaden 2011).

In this study, we address some of those important issues as mentioned. We will also discuss various influences on different types of ENSO separately to address on the mechanism and also related teleconnection with the ISM. This paper is structured as follows. Section 2 describes about Methodology and Data and Results are discussed in section 3. The initial part of section 3 focuses on formulating a Flow Chart, proposing mechanisms for various types of ENSO. The second part covers Climate change period and its relevance with ISM. It discusses spatial pattern as well as temporal behaviour. Section 4 mentions about Conclusions.

\section{Methodology and Data.}

The first part of the study covers a schematic representation that considers several highly cited research and formulates a flow-chart of steps.

In the later part of this study, the method of Multiple Linear Regression analysis with AR (1) noise model is used. In this methodology, with the components of variability, noise coefficients are calculated simultaneously. It is done in a way that the residual is consistent with a red noise model of order one and thus it is possible to minimise noise being interpreted as a signal. Finally, using Student's t-test, measures of the significant levels are calculated. This model is developed by Myles Allen, University of Oxford and this methodology was also used in various climate studies. Of late, Roy and Haigh (2010, 2011, 2012), Roy (2014) and Roy et al. (2016) used this methodology to analyse various climate data. 
Variables and climate indices employed in the regression are Sea Level Pressure (SLP), monthly Sun Spot Number (SSN), Niño3.4, Stratospheric Aerosol Optical Depth (AOD), (indicative of volcanic eruptions) and longer term trends. ENSO data used here are anomaly value. All the data are normalised before using. For SLP, the in-filled HadSLP2 dataset from Allan et al. (2006), which covers the whole globe and available as monthly means from 1850 to 2004 are used. It can also be found from http://www.metoffice.gov.uk/hadobs/hadslp2. Unlike HadSLP1, error estimates are mentioned for HadSLP2, to have ideas about the regions of little confidence. It has been updated upto 2012 using HadSLP2r_lowvar data (http://www.metoffice.gov.uk/hadobs/hadslp2/data/down load.html). It is a version of HadSLP2r and consistent with HadSLP2. The global monthly HadSLP2r data that covers 2005 to 2012, is the NCEP-NCAR Reanalysis data (Kistler etal., 2001), which is adjusted as its average for period 1961-1990 matches with HadSLP2. The deficiency concerning difference in invariance between HadSLP2 and HadSLP2r is adjusted in the recent version of HadSLP2r_lowvardata. Monthly Sun Spot Number (SSN) is used to represent solar cyclic variability and obtained from ftp://ftp.ngdc.noaa.gov/STP/SOLAR DATA/ SUNSPOT_ NUMBERS/INTERNATIONAL/monthly/MONTHLY.PLT. For the ENSO, Niño 3.4 index, obtained from Kaplan et al. [1998] is used which is available since 1856 and can also be found at http://climexp.knmi.nl. In the regression, AOD has been used to represent volcanic eruptions and collected from Sato et al. (1993). It is collected from https://data.giss.nasa.gov/ modelforce/strataer/tau_line.txt and available up to 1999. It is then extended up to 2005 with near zero value. Longer term trend is a rising linear line that represents increasing anthropogenic influence of the 20th century.

For trend analysis, various indices we used are the NAO, SAM, IOD, Nino temperatures (12 and 3.4), EP and CP ENSO, SLP Darwin and Tahiti and regional ISM precipitation. For NAO, DJF value is considered and for the rest, seasonal value of JJA is used. The discriminates for different trend period is used, e.g., 1970, 1976 or 1957, which are based on following justifications: 1970s is in an abrupt drop in SSTs (Thompson et al. 2010); 1976 is the well- 
known Pacific regime shift (Miller, 1994); 1957 could be justified instrumentally as it is termed as International Geophysical Year (IGY) and from that period many other studies started. Other reasons for justification are also mentioned in the text. This study looked at those independent periods.

The monthly EP and CP indices are calculated (Kao and Yu 2009; Yu and Kim 2010) from Extended Reconstructed Sea Surface Temperature (ERSST) dataset (Smith and Reynolds, 2003) that used 1971-2000 climatology and available from 1948 to 2014 . The relevant web links for EP and CP ENSO data are:

http://www.ess.uci.edu/ yu/2OSC/monthly CP index 1948 2014.txt and http://www.ess.uci.edu/ yu/2OSC/monthly EP index 1948 2014.txt Kao and Yu (2009) and Yu and Kim (2010) used a regression-EOF analysis to identify the CP and EP types of ENSO. For CP ENSO, the SST anomalies regressed with the Nino1+2 SST index were first removed from the total anomalies. They considered the Nino1+2 index (010S; $80 \mathrm{~W}-90 \mathrm{~W}$ ) as an estimate to eliminate the influence of the EP ENSO. Then an EOF analysis was applied to obtain the spatial pattern of the CP ENSO. Similarly for EP ENSO, they subtracted the SST anomalies regressed with the Nino4 index from the total SST anomalies before doing the EOF analysis to identify the leading structure of the EP ENSO.

The NAO index from Climate Research Unit (CRU), University of East Anglia is used which is available since 1823. It is developed by Jones et al., (1997) that considered instrumental pressure observations from Gibraltar and south-west Iceland. It is also available from http://www.cru.uea.ac.uk / timo/projpages/ nao_update.htm. The other indices as mentioned are all available from http://climexp.knmi.nl. The ISM data is also present in the Indian Institute

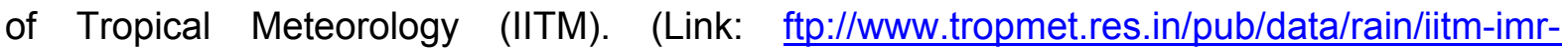
readme.txt). We used ISM rainfall for three arbitrary regions, Central North East (CNE) India (covering five subdivisions), all India rainfall (thirty sub-divisions) and Peninsular rainfall (includes six subdivisions). The details about subdivisions and areas are well documented in 
http://climexp.knmi.nl. For IOD, it is calculated as the difference of SST $\left({ }^{\circ} \mathrm{C}\right)$ from NOAA ERSST (Smith and Reynolds, 2004), version 4 (in situ only) from two regions. It is the SST of a region $\left(39^{\circ}\right.$ to $81^{\circ} \mathrm{E}, 15^{\circ} \mathrm{S}$ to $\left.15^{\circ} \mathrm{N}\right)$ to that from the region $\left(89^{\circ}\right.$ to $101^{\circ} \mathrm{E}, 11^{\circ} \mathrm{S}$ to $\left.1^{\circ} \mathrm{N}\right)$.

To detect significant testing in the trend, we used MannKendall test (Kendall, M. G. (1970), Myles Hollander and Douglas A. Wolfe (1999)).

\section{Results.}

\subsection{Formulation of Flow Chart - Proposed Mechanism:}

Here, I develop a flowchart (Fig. 1), depicting a consolidated overview of atmosphere-ocean coupling, supported by highly cited popular research. Initiated by solar cycle decadal variability how atmosphere-ocean coupling is taking place is shown here. We show the major climate variabilities; viz. solar and ENSO with oval outlines; whereas, the major circulations, responsible for modulating the effect of major variabilities by non-rectangular parallelograms. We show the pathways of the signals by labels that start from ' $A$ ', which is initiated by solar variability and the direction of behaviour change during the steps by '+' (for increase) or '-' (for decrease). The flow chart shows the role of the sun and how atmosphere and ocean coupling regulates various types of ENSO, the Canonic ENSO, Modoki ENSO and Canonic-Modoki ENSO. The related teleconnection with ISM is also presented. Dash dotted lines mark the pathways those are affected by climate change.

Two fundamentally different routes for a solar influence on the troposphere have been proposed: one is the 'Top-Down' mechanism (Haigh and co-workers (2005, 2006, 1996); Baldwin and Dunkerton (2001) and Kodera and Kuroda (2002)) and the other 'Bottom-Up' mechanism (Meehl et al $(2008,2009))$. The ‘Top-Down' solar influence is generated through the stratosphere; whereas, in the 'Bottom-Up' pathway, the Sun can directly affect SST without stratospheric feedback. Roy, I. (2014) elaborately documented more detailed discussions. Frame and Gray (2009) showed using the observation that there is a warming (cooling) in the lower equatorial stratosphere during solar maximum (minimum) years (A, Fig. 1). Haigh and 
co-workers (Haigh, 1996; Haigh et al, 2005; Haigh et al, 2006) showed, an impact on tropospheric mean meridional circulation, characterising an expansion and weakening of the tropical Hadley cells, along with a pole ward shift of the Ferrel cells (A, B, C, Fig. 1). It also leads to coherent changes in the latitudinal location and width of the mid-latitude jet stream (D). Observational work of Brönnimann et al. (2006), also supports such findings. Kodera and Kuroda, (2002) proposed a possible mechanism whereby the solar influence can change equatorial stratosphere through changes in the meridional circulation that involve polar vortex (E). According to them, the sun's heating anomalies can alter the strength of polar upper stratospheric jet, which then subsequently influence the path of upward propagating planetary waves. These waves, depositing their zonal momentum on the poleward side of the jet, weaken the Brewer-Dobson Circulation (BDC) and warm the tropical lower stratosphere in solar maximum years. Solar decadal variability regulates the strength of polar vortex by normal thermal wind balance relationship as labelled here by F. Baldwin et al. (2001) showed perturbations in the polar vortex, are related to polar annular modes $(G)$. They discussed a dynamical mechanism that might communicate stratospheric circulation anomalies downward to the tropospheric surface via polar modes. Meehl et al. $(2008,2009)$ presented a mechanism related to air-sea-radiative coupling involving the sun. They discussed that the spatial asymmetries of solar forcing, induced by cloud distributions, can cause greater evaporation in the subtropics. It consequently causes more moisture transport and intensification of the tropical convergence zone. It thus strengthens the trade winds around tropical Pacific $(H, I)$. Through normal ENSO mechanism, involving deepening of the thermocline $(\mathrm{J}, \mathrm{K})$, it intensifies Walker circulation (L). Shifting of the thermocline is then regulated by oceanic Rossby and Kelvin waves which control the inter-annual nature of ENSO. It is consistent with studies that detected decadal signature in thermocline (Zhang et al., 2006). Some wind triggering mechanism around tropical Pacific responsible for initiation of Rossby and Kelvin wave are needed, though source being still unclear (Vecchi and Soden, 2007). The proposed flowchart suggests the sun could be a possible candidate. Roy and Haigh (2010) also captured similar decadal signature in trade wind (I) in an observational analysis. 
The proposed pathway (K) matches to that with EP ENSO. Ashok et al. (2007); Kao and Yu, (2009) suggested that thermocline shifting is known to be the main driver for EP ENSO. A signature of phase reversal is identified in EP type of ENSO with its major phase transition and barrier was found to change decade to decade (Kao and Yu (2009)).

Weakening of Ferrel Cell is associated with weakening of Aleutian Low (AL). Christoforou and Hameed (1997) showed that solar variability causes shifting the location of AL alongside creating significant differences in intensity (M). Observational analysis by Roy and Haigh (2010) is also consistent with such findings. Decadal variability around AL could be responsible for North Pacific warming $(\mathrm{N})$. Such decadal signature around mid-latitude was captured in observation by Haigh (2003), Frame and Gray (2009). North Pacific Gyre circulation which is wind driven is also affected through AL. Decadal signature in North Pacific Gyre was observed by (Lorenzo et al 2010).

Warming around North Pacific is connected to the shallow ocean conveyor belt which has a rising branch around AL of North Pacific. That shallow ocean conveyor belt is flowing through tropical Pacific and links North Pacific to tropics through ocean pathway (Q). That tropical Pacific part can sometimes be termed as shallow Meridional Ocean circulation (MOC) in the Pacific. It characterizes the equatorward convergence of the pycnocline volume transport across $9^{\circ} \mathrm{N}$ and $9^{\circ} \mathrm{S}$. Zhang et al. (2006), using historical hydrographic data, observed decadal variability in that shallow MOC in Pacific. There are also ocean subduction pathways which could also act as links between tropics to North Pacific mass exchanges. The strength of annular mode can also change the intensity and location of tropospheric jets via usual mechanism and thus influences North Pacific $(\mathrm{O}, \mathrm{P})$ (double-ended arrow show the two-way interactions). It can subsequently modulate mid-latitude ocean gyre through wind stress. The decadal signal around North Pacific could be transported to tropical Pacific via ocean pathway (P, Q, R) to trigger Modoki ENSO feature (R). Lorenzo et al. (2010) showed decadal variations 
in the North Pacific gyre circulation are characterized by a pattern of SST anomalies resembling the CP type ENSO.

Apart from oceanic connections, changes in the mid-latitude jets and Aleutian low can also directly impact CP ENSO, through dynamic variability of the Hadley circulation. All such discussions are consistent with proposed mechanism of CP ENSO. For CP ENSO, as seen in the flow chart atmospheric forcing plays the dominant role as proposed by (Kao and $\mathrm{Yu}$ (2009)) and it has extratropical connections. Aleutian Low could play one dominant role and shown by $\mathrm{S}$ and two mechanisms for extratropical connections are also discussed earlier. Equatorial Ocean Advection Theory (Kug et al. 2009) and Extratropical Forcing Theory (Kao and Yu 2009, Yu and Kim 2011, Yu et al. 2010) are in agreement with those proposed pathways. It is also consistent with the observation that the CP ENSO occur more as events or epochs than as a cycle (Kao and Yu (2009)). The phase locking of CP ENSO with the season, having phase transition in spring (Yu and Kao (2009)) also supports a solar connection. Mantua and Hare (2002) indicated that Pacific in the mid-latitude and tropics is connected via ocean pathway. The pathway that establishes the linkage between tropics (via thermocline shift) and extratropics as shown by T governs ENSO Canonical and Modoki (CM) combined feature. Overall, the flow chart is consistent with studies those detected an underlying quasi-decadal variability in the interannual ENSO (White and Liu, 2008; Zhang et al., 1997; Zhao et al., 2003; Chen et al. 2004). Henyi and Deng, (2011) indicated that decadal signature of ENSO could be coming down from the Polar Vortex modulating the Arctic Oscillation and precipitation around mid to low latitudes of the northern hemisphere $(\mathrm{NH})$.

ISM represents a large-scale heat source located on the equator at a mean position of about 20-30N (around ITCZ) covering CNE region. The response to such a heat source, following the linear theory suggests that it will be related to regional Hadley circulation as well as Walker circulation (Gill 1980). The Walker circulation is related to equatorial heat sources and is remotely regulated by tropical Pacific whereas, the local Hadley circulation shows a direct 
response to the off-equatorial heat source. The strength and location of the monsoon heat source can influence regional Hadley circulation whereas, the Walker circulation over the equatorial Indian Ocean is influenced remotely from the Pacific. It is by the movement of the equatorial heat sources, such as those associated with ENSO. Lee, Shindell et al (2009) studied decadal variability on ITCZ and found enhancement of the strength during active solar periods. Pathways $\mathrm{V}$ and $\mathrm{W}$ indicate about such relationship with ISM and tropical circulations involving ITCZ.

The influence of ENSO in reverse direction is also noted in various studies. The ENSO through Brewer-Dobson circulation can also influence polar vortex $(U)$ and subsequently to extratropics in an inverse pathway and shown in the flow chart. Camp and Tung (2007), showed that during winter, warm-ENSO years are significantly warmer in the stratosphere at the Northern Hemisphere polar and mid-latitudes than the cold-ENSO years. Using a GCM, Sassi et al. (2004) and Taguchi and Hartmann (2006) showed that the warming difference between El Niño and La Niña years is statistically significant and Stratospheric Sudden Warming (SSW) are twice as likely to occur in the El Niño winters than La Niña, thus providing a possible connection between the polar stratosphere and the ENSO. The ENSO can also influence tropospheric jets and polar annular modes were shown by Carvalho et al. (2005), Haigh and Roscoe (2006) (O, P in reverse direction).

Observations as well as model simulations suggested that both types of El Niño modulate the extra-tropical atmosphere though the mechanisms are different. The CP ENSO influence is mainly seen around Southern Hemisphere $(\mathrm{SH})$; though EP in $\mathrm{NH}$. For CP ENSO, the variations in wind etc. are mainly localised around central Pacific (Kao and Yu (2009)). CP El Niño events enhance convective activity in the South Pacific Convergence Zone in austral spring and affects Antarctic surface temperatures and sea ice concentrations (Schneider et al. 2012; Song et al. 2011). Graf, H.-F., and D. Zanchettin (2012) showed CP and EP ENSO have different effect on the Atlantic sector. They showed CP event trigger and NAO-type 
response but not EP. The mechanism how EP ENSO influences extra-tropics differ in two hemisphere. EP ENSO is mainly regulated by thermocline shifting and shows basin wide variation of several features (Ashok, (2007); Kao and Yu (2009)). Hence it is very likely that EP ENSO has potential to perturb planetary scale Rossby waves, which are mainly generated in the $\mathrm{NH}$ due to land ocean contrast. That increase in wave activity causes more interaction with polar vortex making warm polar stratosphere. The NH impacts of EP EI Niño events are studied by Manzini et al. (2006), Garcıa-Herrera et al. (2006) and Randel et al. (2009), among others which showed that EP El Niño events deepen the North Pacific low and enhance planetary wave driving, leading to a weakening of the Arctic vortex in boreal winter. In absence of land ocean contrast in $\mathrm{SH}$, planetary wave activity plays nominal role and hence EP EI Niño events do not impact the extra-tropical SH stratosphere (Hurwitz et al. 2011a). The complications of the flow chart involving several coupling mechanism, suggest why there could be still controversies relating to their individual influences (For CP ENSO: Hegyi and Deng 2011; Xie et al. 2012 and for EP ENSO: Hoerling et al. (1997); Manzini et al. (2006)).

Vecchi and Soden (2007), McPhaden and Zhang (2004), Held and Soden (2006) suggested there is a substantial, decrease in the strength of both Walker and Hadley circulation since the 1950 s as marked here by $X$ and $Y$. It is likely to be reflected simultaneously in ISM as well as ENSO (Z). Roy and Haigh (2012) showed over the similar period, decadal signature around trade wind as demonstrated by $\mathrm{J}$ is missing, probably due to change in mean state. It indicates a weakening of EP ENSO-related mechanism that involves thermocline. A recent study suggests, ENSO Modoki has become more frequent and persistent than Canonic ENSO since the later period of last century (Ashok and Yamagata, (2009); Yeh et al. (2009)). The change in ISM over a similar period is also well documented in various studies (Ashrit et al. 2001, Ashok et al. 2001). The climate change signal via X, Y, Z subsequently affects ISM, using pathways $\mathrm{V}$ and $\mathrm{W}$. There could be various other pathways involved for e.g. QBO etc. as shown in Roy, I (2014), but for clarity, we avoided much complexity. A similar argument is for climate change pathways as shown by the dotted dash line. In the flowchart (Fig. 1), it only 
showed how it is initiated, and more discussion related to climate change is covered in the subsequent section.

Labels agreeing various studies/pathways as discussed here (Fig. 1) are listed underneath to improve clarity:

A: Frame and Gray (2009), Haigh (2003)

A, B, C, D: Haigh (1996, 1999), Haigh et al. (2005), Brönnimann et al. (2006)

E: Kodera and Kuroda (2002)

F: Usual mechanism following thermal wind balance.

G: Baldwin and Dunkerton (2001).

H, I: Meehl et al. (2008, 2009).

I: Roy and Haigh (2010)

J, K, L: Normal ENSO (inter-annual) mechanism.

K: Kao and Yu (2009); Ashok et al. (2007)

M: Christoforou and Hameed (1997), Roy and Haigh (2010).

N, P: Haigh (2003), Frame and Gray (2009).

O, P: Carvalho et al. (2005), Haigh and Roscoe (2006)

$\mathbf{O}, \mathbf{P}, \mathbf{Q}, \mathbf{N}$ : Usual ocean-atmosphere interaction involving wind stress.

R: Kao and Yu (2009); Yu and Kao (2009)

S: $\quad K a o$ and $Y u(2009)$

T: $\quad$ Mantu and Hare (2007)

U: Camp and Tung (2007); Sassi et al. (2004); Taguchi and Hartmann 
(2006)

V, W: Gill (1980).

X, Y: Held and Soden (2006), Vecchi and Soden (2007), McPhaden and Zhang, (2004).

Z: Ashok and Yamagata (2009), Yeh et al. (2009) 


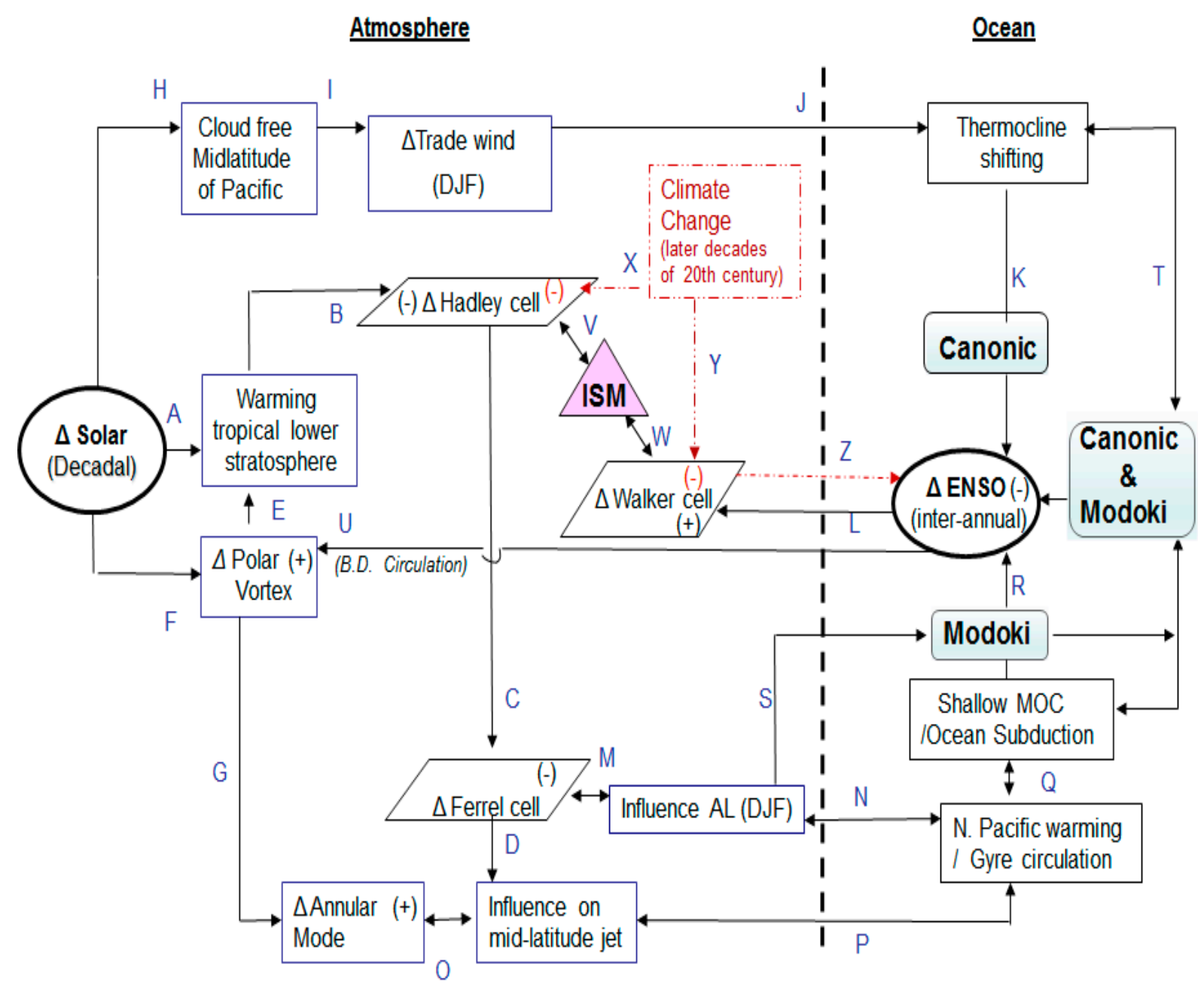

Fig.1. Flow chart showing the role of the sun in atmosphere and ocean coupling mainly during DJF and the possible mechanism for Canonic ENSO, Modoki ENSO and Canonic-Modoki ENSO. ENSO-related teleconnection (e.g., ISM) affected by climate change period is shown by dash-dotted line. 
Table 1 indicates how each link is evidenced by observation, explained by a mechanism or only be viewed as a hypothesis at this stage. Some pathways are partly based on observation or model experiments but still needs improvements are also kept as hypothesis stage.

Table -1: Indicating whether the pathways are hypothesised or evidenced.

\begin{tabular}{|c|c|c|c|}
\hline & & $\mathrm{Mec}$ & nism \\
\hline & & Explained & Hypothesised \\
\hline $\begin{array}{r}\text { Lower } \\
\text { Stratosphere } \\
(\mathrm{A}-\mathrm{D}, \mathrm{H}, \mathrm{I}, \mathrm{M})\end{array}$ & $A, B, C, D, H, I, M$ & $A, B, C, D, I$ & $\mathrm{H}, \mathrm{M}$ \\
\hline $\begin{array}{rr}(\mathrm{A}-\mathrm{I}, \mathrm{M}, \mathrm{O}) & \text { Upper } \\
& \text { Stratosphere } \\
(\mathrm{E}-\mathrm{G}, \mathrm{O})\end{array}$ & $F, G$ & $E, F, O$ & \\
\hline $\begin{array}{l}\text { Atmosphere-ocean } \\
\text { Coupling } \\
(\mathrm{J}-\mathrm{L}, \mathrm{N}, \mathrm{P}-\mathrm{T}, \mathrm{U}-\mathrm{W})\end{array}$ & $\mathrm{J}, \mathrm{K}, \mathrm{L}, \mathrm{U}, \mathrm{S}, \mathrm{P}$ & $\mathrm{J}, \mathrm{K}, \mathrm{L}, \mathrm{N}, \mathrm{T}, \mathrm{V}, \mathrm{W}, \mathrm{Q}$ & $N, P, Q, R, S$ \\
\hline $\begin{array}{l}\text { Climate Change } \\
(X-Z)\end{array}$ & $X, Y, Z$ & Z & \\
\hline
\end{tabular}


3.2. ISM and Climate change

3.2.1. Results of Regression:

a)

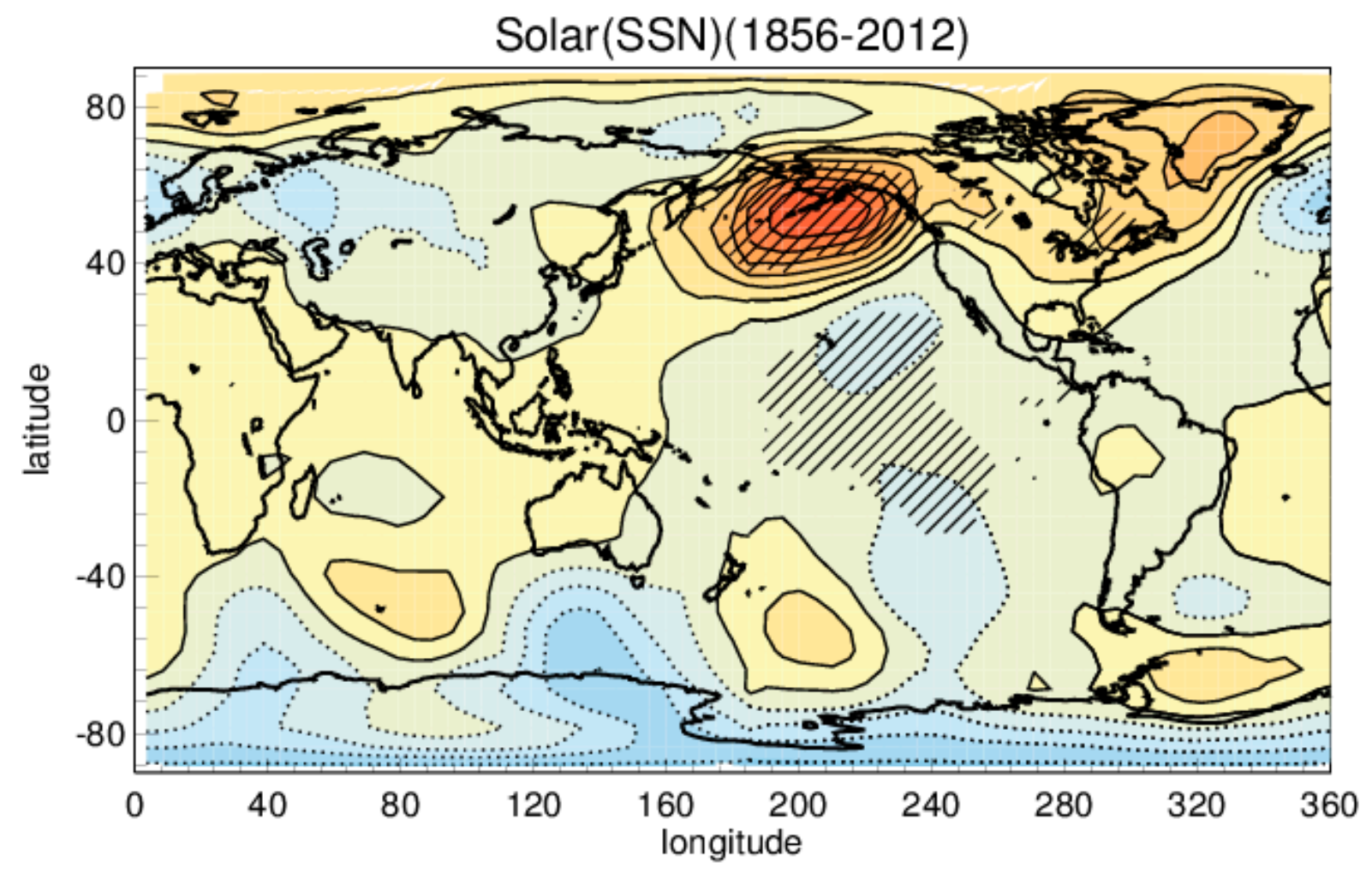

b)

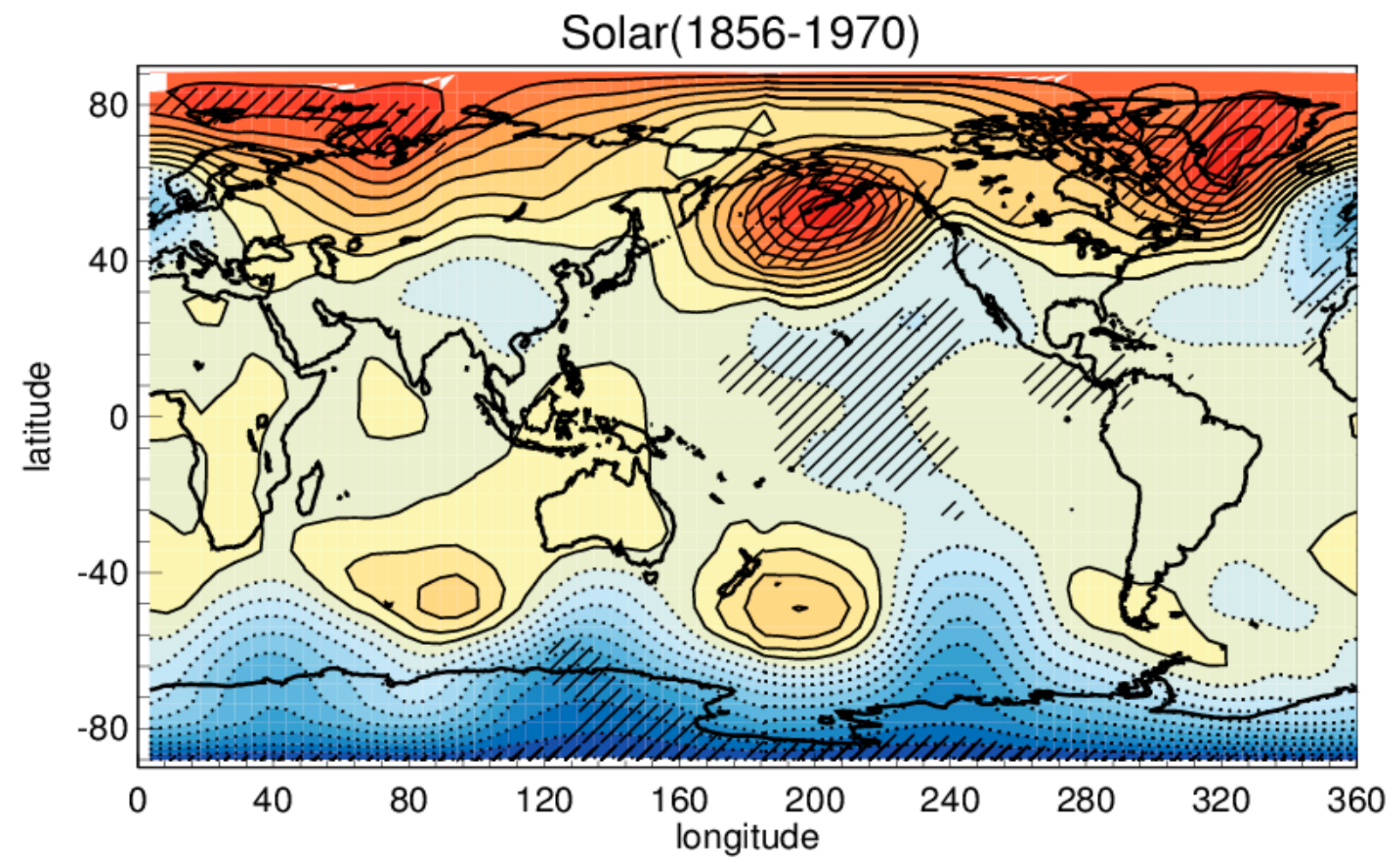


c)
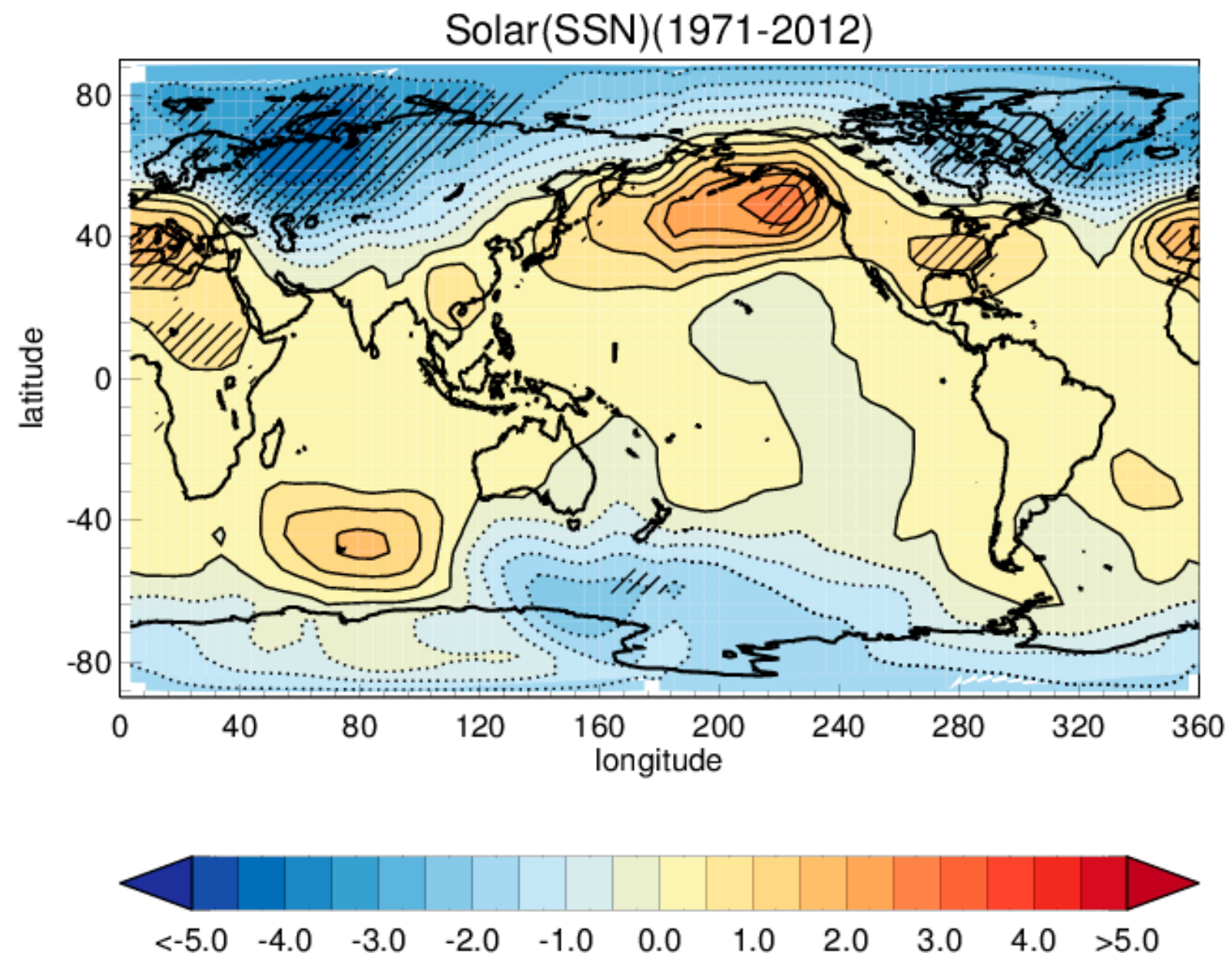

Fig. 2. The solar cycle signal (max-min, hPa) in DJF HADSLP2 data obtained from a multiple linear regression analysis using monthly SSN. Other indices used are ENSO, AOD (volcano) and trend. Top panel (a) shows a result for the entire period (1856-2012) and bottom panel (b) for an earlier period (1856-1970) and (c) a latter period (1971-2012). Dotted lines indicate negative contours. Shaded regions are estimated significant at the $95 \%$ level using a twosided Student's t-test.

ENSO Modoki has become more frequent and persistent than Canonic ENSO since the 1970s (Ashok and Yamagata, (2009); Yeh et al. (2009)). We carried three separate MLR analyses on SLP data: for whole period (Fig. 2a); before and after 1970 (Fig. 2b and Fig. 2c respectively). It is for exploring possible mechanism focussing only on DJF. Strong signal around AL is noticed in all plots. Coincidentally, the location of PDO (manifest as SST) and 
ENSO (manifest as SLP) also matches those places with their cold phases having similarly signed signature to that of high solar years. Interestingly, such strong solar signature in SLP around AL during northern winter is robust and found insensitive to various methodologies and time periods. Roy et al. (2016) did seasonal analysis and showed that solar signal around AL is only present during DJF. For ENSO also, they showed the signal around AL is strongest during DJF; for other seasons it is weak and mostly insignificant. Fig. $2 b$ and Fig. $2 c$ suggest solar signal around central tropical Pacific was different in those two periods. A small but significant decadal signature is present around central Pacific before 1970 (Fig. 2b) that could play a role in triggering trade wind. Fig. $2 a$ for the whole period however indicates significant signal though weaker than Fig. 2b. Such solar signal on trade wind, responsible for initiating ENSO through indirect dynamical coupling was discussed in details by Roy, (2014). Instigating oceanic Rossby and Kelvin waves it has a potential in shifting thermocline and subsequently EP ENSO. Such decadal scale signature could be present in addition to the inter-annual variability of EP ENSO that is mainly controlled by oceanic Kelvin and Rossby wave movements. Decadal signature on thermocline is also noted in various studies (Zhang et al., (2006). It is also consistent with the earlier discussion, (Yu and Kao, 2009) who indicated that for EP type, the phase transition and barrier changes decade to decade and it is mainly regulated by thermocline shifting. That solar signature is absent since 1971 (Fig. 2c) and could be one possible cause for dominance of CP ENSO over EP (Ashok and Yamagata, (2009); Yeh et al. (2009)). 

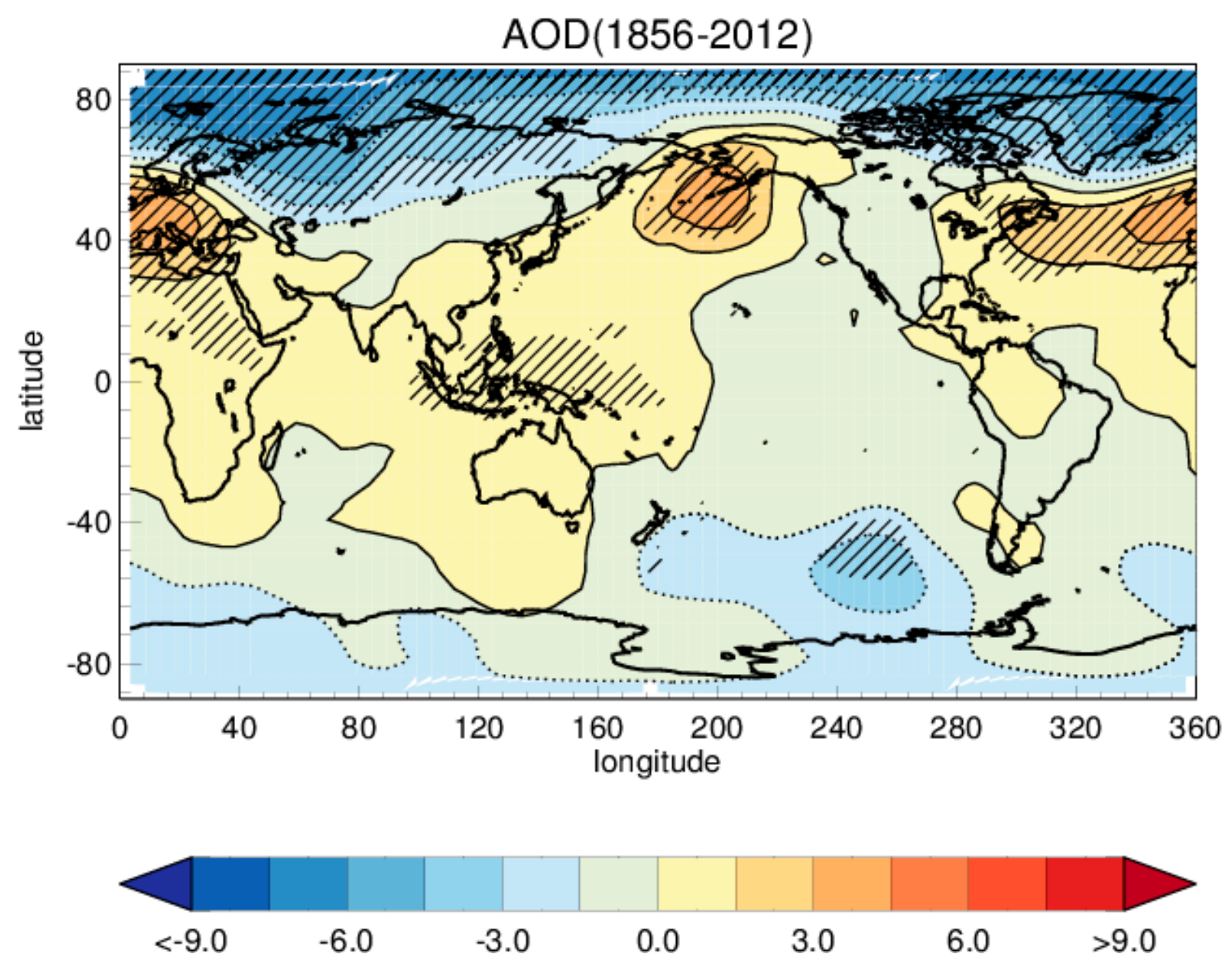

Fig. 3. Same as Fig 2a but it presents the signal due to volcano (AOD).

Fig. 3 shows the result due to volcano over the period 1856 to 2012. The influence of explosive volcanos on ENSO phase was discussed in details by Roy, I (2016), that covered observational as well as modelling experiments. Positive NAO pattern is clearly distinguished for active volcanos. Two major volcanos erupted during 1981 and 1992, which were strongest ever in the record of past 150 years. Contrary to the earlier eruptions, those two also coincided with the active phases of high solar cycles. It is suggested that the relationship between NAO and ISM has become stronger, over about the same period the relationship between ISM and ENSO has weakened (Chang et al, 2001). The result of regression suggests two explosive volcanos during latter decades of last century could be one responsible factor for such change of behaviour of ISM. Several studies have suggested that there was a major shift in the largescale circulation during the mid-1970s to early 1980s, in both hemispheres which include 
ENSO and polar modes (e.g. Yeo et al. 2015). Due to an absence of volcanos in current decades, such connection on ISM via regional Hadley circulation is absent, suggesting it could be one possible cause that correlation between ENSO and ISM is reverted since the late 1990s (Yim et al (2013)). It is also noted that precipitation has likely increased over the last decade, after reversing the drying trend that happened from the mid of the 1970 s to mid of 1990s (IPCC, 2013).

It is suggested that the increase of CP ENSO during latter decades of last century could be due to parts of decadal nature variability (McPhaden 2011). It is also supported by Fig. 2 and could be via regional Hadley circulation. Positive NAO pattern for the sun is clearly distinguished in the later period (Fig. 2c), which is different during an earlier period (Fig. 2b). Bjerknes (1966) showed that the major warming along the central and equatorial Pacific during boreal winter is often accompanied by an anomalous strength of the midlatitude westerlies. There is a two-sided interaction. The anomalously great heat from the equatorial ocean to the rising branch of the Hadley circulation would strengthen the cell. It will generate above normal flux of angular momentum to the westerly winds around midlatitude belt. Thus, warming in the tropical Pacific can strengthen the midlatitude westerly jets during boreal winter and subsequently can favour positive phase of the NAO. Following the similar mechanism positive phase of the NAO can also favour positive phase of CP ENSO. It supports that increase of CP ENSO during latter decades (as initiated via positive phase of NAO) could be due to parts of decadal nature variability (McPhaden 2011)

\subsubsection{Time series Analysis}

The ISM-ENSO relationship is found to have common changing points in the 1970s. Though weakened since then showed a recovery in the late 1990s (Yim et al (2013)). An analysis based on time series of various modes of climate variability is performed with particular emphasis on the period 1976-1996, to investigate such connection further. It covers two full 
solar cycles, (cycle number 21 and 22) starting from one solar minimum (1976) and ending with another solar minimum (1996). The consecutive solar peak years are 1979 and 1989 with one minimum in between (the year 1986). During that period, two major volcanos erupted during active years of stronger solar cycles.

Figure 4 shows normalised time series of various seasonal modes of climate variability those might be related to different types of ENSO (EP or CP) and also regional ISM rainfall, as shown by their subtitles. Top panel (Fig. 4(i)) is during period 1871-2011 and the bottom panel (Fig. 4(ii)) is for 1957-2012. For NAO, DJF value is considered and for the rest seasonal value of JJA is used. Five year running mean of each series is marked by red in each panel.

A trend line is plotted during 1976-1996 for all series of bottom panel and shown by a blue dashed line. The period of 1976-1996 is demarcated by black dash lines in Fig. 4(ii).

a) Nino3.4

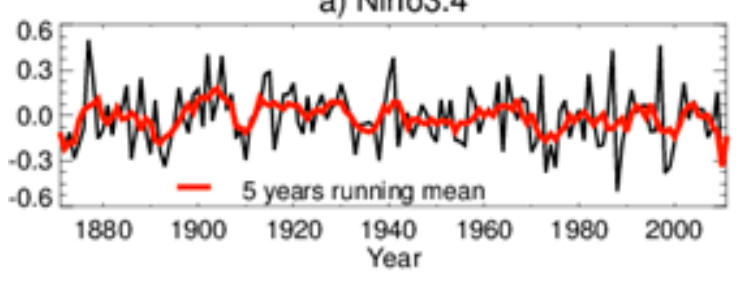

c) SLP(Darwin)

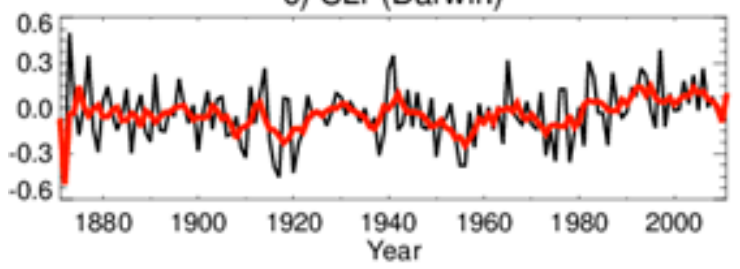

e) IOD

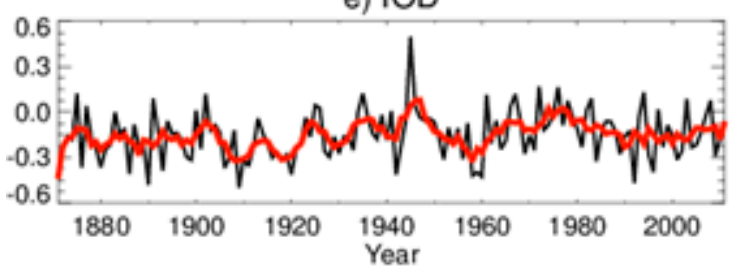

g) ISM Precipitation(All India)

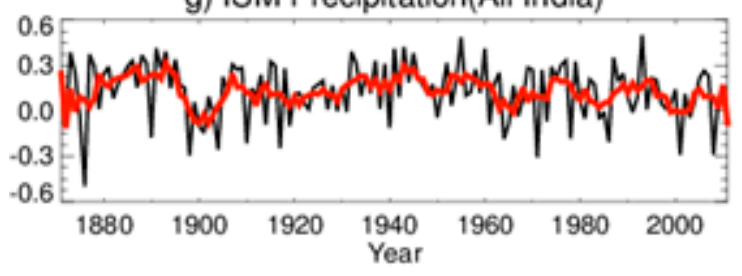

b) Nino12

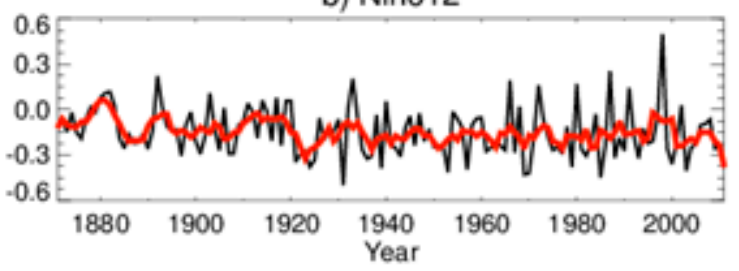

d) SLP(Tahiti)

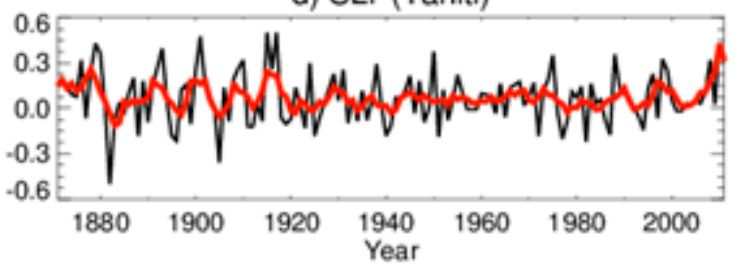

f) ISM Precipitation(CNE)

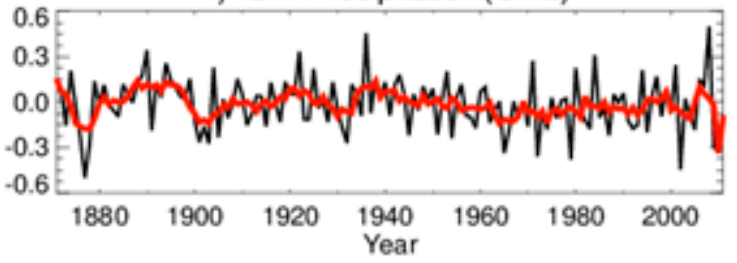

h) ISM Precipitation(South Penninsular)

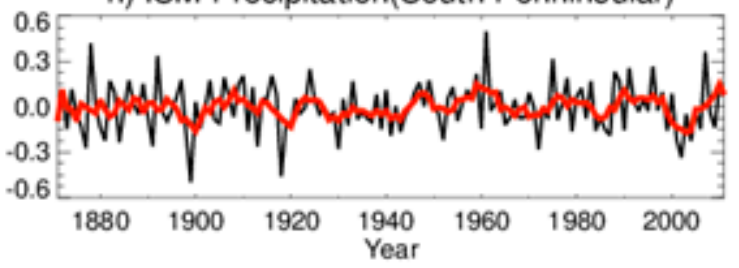



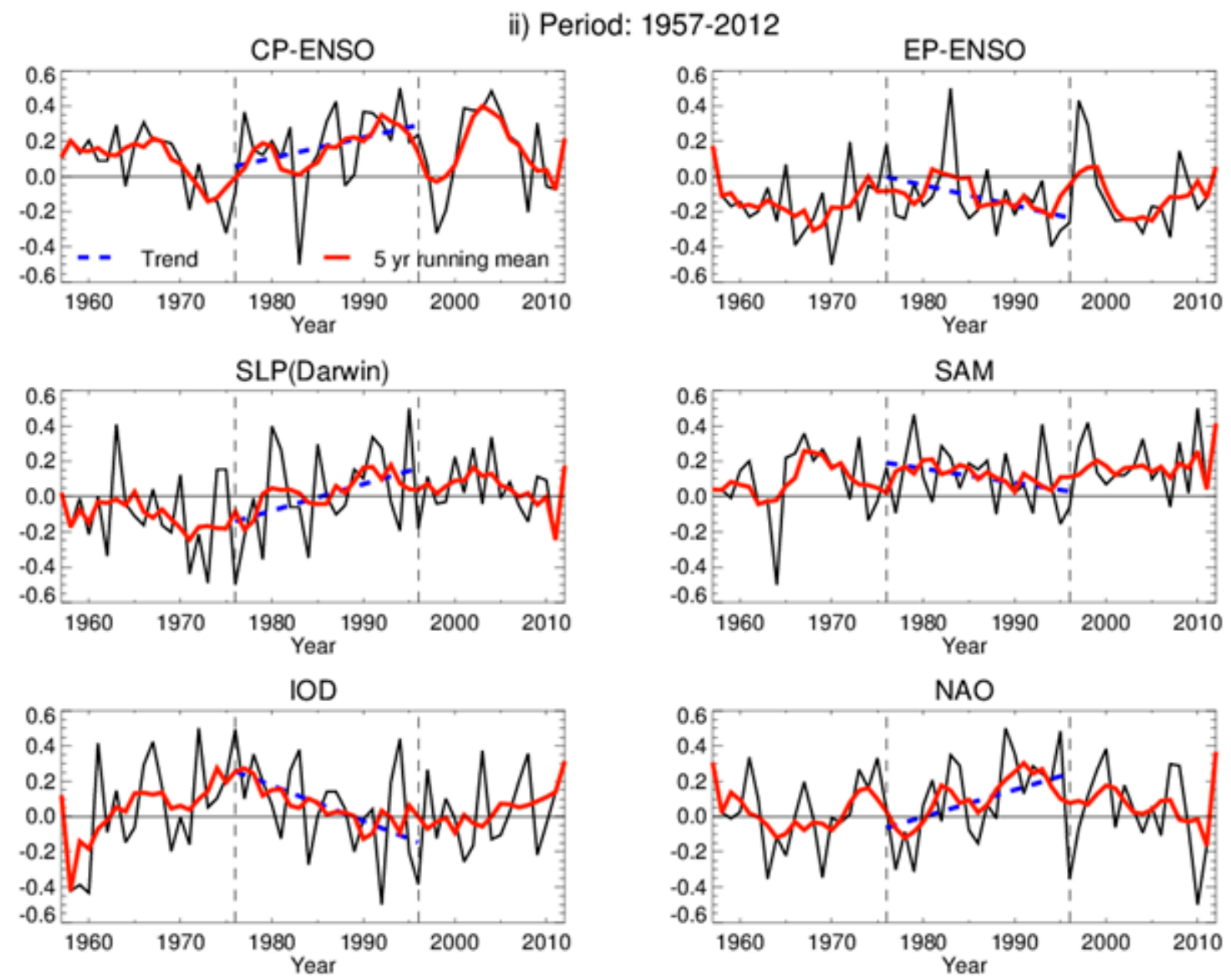

Fig.4. Normalised time series of various seasonal modes of climate variability i) during the period 1871-2011 (top panel) and ii) period 1957-2012 (bottom panel). For all cases, JJA value is considered, while for NAO, it is DJF. Five year running mean of each series is marked by red in each panel. A trend line is plotted during 1976-1996 for all series of bottom panel and shown by a blue dashed line. Black dash lines demarcate the time period of 1976-1996.

Noting Fig. 4(i), it can be stated that there is no apparent clear trend in any of those time series for the whole of the record. We could not identify decreasing trend of ISM (IPCC, 2013) in the arbitrary chosen regional ISM rainfall. It could be due to a precise location of CNE India, covering the ITCZ that only showed the decreasing trend in a spatial pattern (Bollasina et al. (2011) and Goswami (2006)). The time series of regional ISM considered here might have other opposing local influences. Interestingly, when the focus is around 1976-1996, a clear 
trend is noticed for SLP Darwin and IOD (Fig. 4(i)). Hence, we analyse it further in Fig 4(ii) considering shorter record (1957-2012) demarcating that 20 years period.

We presented time series of few other parameters that we thought might be linked to those two parameters (IOD and SLP Darwin). We chose SLP around Darwin because an increase in SLP here strengthens ITCZ. The rise in pressure gradient between Darwin and ITCZ enhances the flow of moist reach ocean air. More air from the Indian Ocean converge towards the land region of India and increase rainfall. CP and EP ENSO series are constructed since 1948 ((Kao and Yu 2009; Yu and Kim 2010) and we presented those in Fig. 4(ii) as those are more relevant to our discussion. Among those parameters, there is a clear rising trend for $\mathrm{CP}$ ENSO, NAO, SLP Darwin with a decreasing trend for EP ENSO and IOD. All the parameters suggest nominal, insignificant rising trend over the whole period (1957-2012).

CP ENSO suggested a clear upward trend (11\% per decade, increased significantly; for whole period it is $1.4 \%$ ) which is consistent with the observation that ENSO Modoki became more familiar since the 1970 s up to late 1990s. It is in agreement with rising trend of NAO $(+15 \%$ per decade, whole 1.3\%). The connection between CP ENSO and NAO, both suggest increasing trend, agrees with the proposed mechanism of Bjerknes (Bjerknes (1966) as discussed earlier). Annular modes in $\mathrm{NH}$ have exhibited pronounced trends toward high-index polarity also documented by Hurrell (1995) and Thompson et al. (2000). The EP ENSO, on the other hand, shows a decreasing trend (-11\% per decade, but not significant; whole $0.4 \%)$.

The influence of ENSO Modoki on Southern Hemisphere storm track activity during JJASO (June- July-August-September-October) was discussed by Ashok et al. (2009). It showed El Niño Modoki introduces a blocking over central eastern Australia which subsequently suppresses the regional storm track activity. Following an increase of ENSO Modoki since the 1970s, it would undoubtedly suggest a rise in SLP around Darwin, Australia as also noticed Fig. 4 (ii) (trend $=+15 \%$ per decade, whole 3.8\%). Roy and Collins (2015) also noticed that 
SLP of Darwin is strongly influenced during later periods. Thus, ENSO Modoki through blocking over Australia, one end of IOD, can have potential to influence IOD and subsequently ISM (trend of IOD $=-20 \%$ per decade, significant at $95 \%$ level; whole $.3 \%$ ). Following the definition of IOD as used here, the direction of the trend for IOD and SLP of Darwin suggests a consistent result. There could be an argument that if SLP of Darwin has the potential to influence ISM, then a clear trend observed there should also be seen in ISM rainfall time series. But it is not the case because ISM is not only regulated by moisture convergence from the Indian Ocean alone. Large-scale circulation features like Walker circulations and Regional Hadley circulation also play dominant roles, apart from other local influences. All those forcing acts in a complex non-linear manner to produce the actual response on ISM and hence no clear trend is noticed.

The response relating to Hadley cell and upper air midlatitude westerlies can be explained by the mechanism proposed by Bjerknes (Bjerknes (1966)) and is expected to be strongest in the winter hemisphere due to greater baroclinicity. Hence, it is also captured in the strength of SAM. The ENSO Modoki which is dominant since the 1970s, though suppresses rainfall over India but enhances over North and South America. Rainfall in central Argentina is also increased owing to the strengthened upper air westerlies (Ashok et al. (2009)). Amita et al. (2015) studied trends in SAM during1949-2013 and found that the data from post-1982 does not show significant long-term trends. It is because of opposing nature of the strength of westerlies around the whole of the mid-latitude to that from Darwin of Australia. That could be one responsible factor to suggest null results for SAM trend when considered in zonal sense. It is consistent with the current analysis as we also could not identify a significant rising trend for SAM (trend is only $-8 \%$ per decade and insignificant) during that period (whole trend is $+2 \%)$.

From the last 100 years of Darwin's mean sea-level pressure record of last century, Trenberth and Hoar (1996) reported that the Darwin pressure has tended to be above its long-term 
normal since 1977 and suggested it might be due to the influence of the enhanced greenhouse effect on the climate system. However, contrary to that, Harrison and Larkin (1997) indicated about the impact of natural variability on the tropical Pacific.

All these studies suggest, local N-S Hadley circulation, as manifest as NAO in the NH and IOD in $\mathrm{SH}$ may have played a role in modulating ISM in later decades of last century.

\section{Discussion.}

We present a flow chart depicting atmosphere and ocean coupling. Based on highly cited popular research, possible mechanisms for Canonic ENSO, Modoki ENSO and CanonicModoki ENSO are proposed. Initiated by decadal solar variability how tropospheric circulations (Hadley and Walker circulation) and mid-latitude jets are influenced are discussed. Such flow chart will help to improve our understanding about different types of ENSO in temporal as well as spatial scale. It will also benefit the modelling group to improve the representation of the ENSO in models. The subsequent teleconnections by ENSO for eg., on ISM, is also presented. Focusing on later two decades of the last century, we discuss how such teleconnection could have disrupted. During that period, the role of explosive volcanos and that of the sun both triggered positive phase of the NAO, which could be one of the several factors for possible disruption. We also show there is a significant rising trend for CP ENSO, NAO and SLP around Darwin of Australia. The overall study also addresses how local N-S Hadley circulation, as manifests as NAO in the NH and IOD in the SH could have played a role in modulating ISM in later decades of the twentieth century.

\section{References.}

Allan, R. and Ansell, T., A new globally complete monthly historical gridded mean sea level pressure dataset (HadSLP2): 1850-2004, J. Climate, 19(22), 5816-5842, (2006). 
Amita, P., Kripalani RH, Preethi, B and Pandithurai, Potential role of the February-March Southern Annular Mode on the Indian summer monsoon rainfall: a new perspective. Climate Dynamics. DOI: 10.1007/s00382-015-2894-5, (2015).

Ashok K, Behera SK, Rao SA, Weng H, Yamagata T, El Niño Modoki and its possible teleconnections. J Geophys Res 112:C11007. doi:10.1029/2006JC003798, (2007).

Ashok K, Tam CY, Lee WJ. ENSO Modoki impact on the Southern Hemisphere storm track activity during extended austral winter. Geophysical Research Letter 36: L12705, DOI: 10.1029/2009GL038847, (2009).

Ashok, K., Guan, Z. and Yamagata, T., Impact of Indian Ocean Dipole on the Relationship between the Indian Monsoon Rainfall and ENSO. Geo. Res. Lett. 28, 23, 4499-4502, (2001).

Ashok, K and Yamagata T, Climate change: The El Niño with a difference Nature 461, 481484. doi:10.1038/461481a, (2009).

Ashrit RG, Rupa Kumar K, Krishna Kumar K. ENSO-monsoon relationships in a greenhouse warming scenario. Geophysical Research Letters 28(9): 1727-1730, (2001).

Baldwin, M.P. and Dunkerton, T.J., Stratospheric harbingers of anomalous weather regimes. Science, 294, 5542, 581-584, DOI: 10.1126/science.1063315, (2001).

Bjerknes, J., A possible response of the atmospheric Hadley circulation to equatorial anomalies of ocean temperature, Tellus, 18, 4, 820-829, DOI: 10.1111/j.21533490.1966.tb00303, (1966).

Bollasina, M.A, et al. Anthropogenic Aerosols and the Weakening of the South Asian Summer Monsoon, Science, 502, 334, DOI: 10.1126/science.1204994, (2011).

Brönnimann, S., Ewen, T., Griesser, T., and Jenne, R., Multidecadal signal of solar variability in the upper troposphere during the 20th century, Space Sci. Rev., 125(1-4), 305-317, 305317, doi: 10.1007/s11214-006-9065-2, (2006).

Brown JN, Mclntosh PC, Pook MJ, Risbey JS., An investigation of the links between ENSO flavors and rainfall processes in Southeastern Australia. Monthly Weather Review 137: 37863795, (2009).

Cai W, Cowan T., La Niña Modoki impacts Australia autumn rainfall variability. Geophysical Research Letter 36: L12805, DOI: 2009GL037885, (2009). 
Camp, C.D. et al., Stratospheric polar warming by ENSO in winter: A statistical study, Geophys. Res. Lett., 34, L04809, doi: 10.1029/2006GL028521, (2007).

Carvalho L.M.V., Jones, C and Ambrizzi, T., Opposite phases of the Antarctic Oscillation and relationships with intraseasonal to interannual activity in the tropics during the austral summer, J. of Clim., 18, 702-718, DOI: 10.1175/JCLI-3284.1, (2005).

Chang, C. P., P. Harr, and J. Ju, Possible roles of Atlantic circulations on the weakening Indian monsoon rainfall-ENSO relationship. J. Climate, 14, 2376-2380, (2001).

Chang CWJ, Hsu HH, Sheu WJ., Interannual mode of sea level in South China Sea and the roles of El Niño Modoki. Geophysical Research Letter 35: L03601, DOI: 10.1029/2007GL032562, (2008).

Chen, D., Cane, M. A., Kaplan, A., Zebiak, S. E. \& Huang, D. J. Predictability of El Niño over the past 148 years. Nature 428, 733-736 (2004).

Christoforou, P. and Hameed, S., Solar cycle and the Pacific 'centers of action', Geophys. Res. Lett., 24(3), 293-296, DOI: 10.1029/97GL00017, (1997).

Chung, C. E. and V. Ramanathan, Weakening of the North Indian SST gradients and the monsoon rainfall in India and the Sahel, J. Clim. 19, 2036, (2006).

Frame, T.H.A. and Gray, L.J., The 11-year solar cycle in ERA-40 data: an update to 2008, J. Climate, Early online release, DOI: 10.1175/2009JCLI3150.1, (2009).

Garcl'a-Herrera R, Calvo N, Garcl'a RR, Giorgetta MA, Propagation of ENSO temperature signals into the middle atmosphere: a comparison of two general circulation models and ERA40 reanalysis data. J Geophys Res 111:D06101. doi:10. 1029/2005JD006061, (2006).

Gill A. E., Some simple solutions of heat induced tropical circulations. Q J R Meteorol. Soc 106: 447-462, (1980).

Goswami, B.N., V. Venugopal, D. Sengupta, M. S. Madhusoodanan, P. K. Xavier, Increasing Trend of Extreme Rain Events Over India in a Warming Environment, Science 314, 1442, (2006).

Graf, H.-F., and D. Zanchettin (2012), Central Pacific El Niño, the "subtropical bridge," and Eurasian climate, J. Geophys. Res., 117, D01102, doi:10.1029/2011JD016493. 
Haigh, J. D., Blackburn, M., and Day, R., The response of tropospheric circulation to perturbations in lower-stratospheric temperature, J. Climate, 18(17), 3672-3685, (2005).

Haigh, J. D., The impact of solar variability on climate, Science, 272(5264), 981-984, (1996).

Haigh, J. D., A GCM study of climate change in response to the 11-year solar cycle, Q. J. Roy. Meteor. Soc., 125(555), 871-892, (1999).

Haigh, J.D. and Roscoe, H.K., Solar influences on polar modes of variability, Meteorol. Z., 15, 3, 371-378, doi: 10.1127/0941-2948/2006/0123, (2006).

Haigh, J. D., The effects of solar variability on the Earth's climate, Philos. T. R. Soc. A., 361(1802), 95-111, (2003).

Harrison, D.E. and Larkin, N.K. Darwin sea level pressure, 1876-1996: Evidence for climate change? Geophysical Research Letters 24: doi: 10.1029/97GL01789. issn: 0094-8276, (1997).

Hegyi BM, Deng Y, A dynamical fingerprint of tropical Pacific sea surface temperatures on the decadal-scale variability of cool season Arctic precipitation. J Geophys Res 116:D20. doi: 10.1029/2011JD016001, (2011).

Held and Soden, Robust Responses of the Hydrological Cycle to Global Warming. Journal of Climate. 19, 5686-5699, (2006).

Hill, K. J, A. S. Taschetto, and M. H. England, South American rainfall impacts associated with inter-El Niño variations, Geophysical Research Letters, 36, L19702, doi: 10.1029/2009GL040164, (2009).

Hoerling MP, Kumar A, Zhong M, El Niño, La Nin a, and the nonlinearity of their teleconnections. J Climate 10:1769-1786, (1997).

Huang, P. et al. Patterns of the seasonal response of tropical rainfall to global warming. Nature Geosci. 6, 357-361 (2013).

Hurwitz MM, Newman PA, Oman LD, Molod AM, Response of the Antarctic stratosphere to two types of El Niño events. J Atm Sci 68:812-822. doi:10.1175/2011JAS3606.1, (2011a).

Hurrell et al., Influence of variations in extratropical wintertime teleconnections on northern hemisphere temperature, Geophysical Research Letter, DOI: 10.1029/96GL00459, (1996). 
IPCC, 2013: Climate Change, The Physical Science Basis. Contribution of Working Group I to the Fifth Assessment Report of the Intergovernmental Panel on Climate Change, Cambridge University Press, Cambridge, United Kingdom and New York, NY, USA, 1535 pp, doi: 10.1017/CBO9781107415324, (2013).

Jones, P.D. Jonsson, T and Wheeler, D, Extension of the North Atlantic Oscillation using early instrumental pressure observations from Gibraltar and southwest Iceland, Int. J. Climatol. 17:1433-1450, (1997).

Kao H-Y, Yu J-Y., Contrasting eastern-Pacific and central-Pacific types of El Nino. Journal of Climate, 22: 615 - 632, (2009).

Kaplan, A., Cane M., Kushnir Y., Clement A., Blumenthal M., and Rajagopalan B., Analyses of global sea surface temperature 1856-1991, J. of Geophys. Res., 103, 18,567-18,589, (1998).

Kendall, M. G., Rank Correlation Methods, 4th ed. London: Griffin, (1970).

Kistler, R., Collins, W., Saha, S., White, G., Woollen, J., Kalnay, E. ,Chelliah, M., Ebi- suzaki, W., Kanamitsu, M., Kousky, V., van den Dool, H., Jenne, R., Fiorino, M., The NCEP-NCAR 50-year reanalysis: monthly means, CD-ROM and documentation. Bull. Am. Meteorol. Soc. 82, 247-267, (2001).Kodera, K. and Kuroda, Y., Dynamical response to the solar cycle. J. Geophys. Res., 107, D24, 4749, doi:10.1029/2002JD002224, (2002).

Kripalani RH and A Kulkarni, Climate impact of El Nino / La Nina on the Indian Monsoon: A new perspective, Weather, 52, 39-46, (1997).

Kug J-S, Jin F-F, An S-I, Two types of El Niño events: cold tongue El Niño and warm pool El Niño. J Climate 22:1499-1515, (2009).

Kumar KK, Rajagopalan B, Cane MA, On the weakening relationship between the Indian Monsoon and ENSO. Science 284 (5423): 2156-2159, (1999).

Larkin NK, Harrison DE., On the definition of El Niño and associated seasonal average U.S. weather anomalies. Geophysical Research Letters, 32, L13705, DOI: 10.1029/ 2005GL022738, (2005).

Lean, J. and Rind, D., Earth's response to a variable Sun, Science, 292, 5515, 234-236, (2001). 
Lee, J.N., D.T. Shindell, and S. Hameed, The influence of solar forcing on tropical circulation. J. Climate, 22, 5870-5885, doi:10.1175/2009JCLI2670.1, (2009).

Liu, X., and M. Yanai, Relationship between the Indian monsoon rainfall and the tropospheric temperature over the Eurasian continent. Quart. J. Roy. Meteor. Soc., 127, 909-937, (2001).

Lorenzo E.D., K. M. Cobb, J. C. Furtado et al., Central Pacific El Niño and decadal climate change in the North Pacific Ocean, Nature GeoScience, 1-4, DOI: 10.1038/ NGEO984, (2010).

Maity, R. and Kumar D. N., Bayesian dynamic modelling for monthly Indian summer monsoon rainfall using El Niño-Southern Oscillation (ENSO) and Equatorial Indian Ocean Oscillation (EQUINOO). J. Geophys. Res. 111:D07104, (2006).

McPhaden MJ, Lee T, McClurg D., El Nino and its relationship to changing background conditions in the tropical Pacific Ocean. Geophysical Research Letters. 38: L15709, DOI: 10.1029/2011GL048275, (2011).

Manzini E, Giorgetta MA, Esch M, Kornblueh L, Roeckner E, The influence of sea surface temperatures on the Northern winter stratosphere: ensemble simulations with the MAECHAM5 model. J Climate 19:3863-3881, (2006).

Mantua, N.J. and Hare, S. R. (2002): The Pacific Decadal Oscillation. Journal of Oceanography, 58, 1, 35-44.

McPhaden, M. J, and Zhang, D., Pacific Ocean circulation rebounds, Geophys. Res. Lett., 31, L18301, doi:10.1029/2004GL020727, (2004).

Meehl, G. A., Arblaster, J.M., Branstator, G., and van Loon, H., A coupled air-sea response mechanism to solar forcing in the Pacific region, J. Climate, 21(12), 2883-2897, (2008).

Meehl, G. A., Arblaster, J. M., Matthes, K., Sassi, F., and van Loon, H., Amplifying the Pacific Climate System Response to a Small 11-Year Solar Cycle Forcing. Science, 325, 1114-1118, doi:10.1126/science.117287, (2009).

Miller J., D. R., Cayan, T. P. Barnett, N. E. Graham and J. M. Oberhuber, The 1976-77 climate shift of the Pacific Ocean. Oceanography, 7, 1, (1994). Myles Hollander and Douglas A. Wolfe, Nonparametric Statistical Methods, 2nd Edition,_Wiley-Interscience, ISBN-10: 0471190454, ISBN-13: 978-0471190455, (1999).

Ramanathan, V. et al., Atmospheric brown clouds: Impacts on South Asian climate and hydrological cycle. Proc. Natl. Acad. Sci. U.S.A. 102, 15, 5326, (2005). 
Randel WJ, Garcia R, Calvo N, Marsh D, ENSO influence on zonal mean temperature and ozone in the tropical lower stratosphere. Geophys Res Lett 36:L15822. doi:10.1029/ 2009GL039343, (2009).

Roy, I. and Tedeschi, R. G., 'Influence of ENSO on regional ISM precipitation - local atmospheric Influences or remote influence from Pacific', Atmosphere, 7, 25; doi:10. 3390/atmos7020025, (2016).

Roy, I. and Tedeschi, R. G. and Collins, M., 'Asymmetry in different types of ENSO and related teleconnection with the Indian Summer Monsoon', International Journal of Climatology, DOI: 10.1002/joc.4811, (2016).

Roy and Collins, On identifying the role of Sun and the EI Niño Southern Oscillation on Indian Summer Monsoon Rainfall, Atmos. Sci. Let.,16: 162-169, DOI: 10.1002/asl2.547, (2015).

Roy, I. 'The role of the sun in atmosphere-ocean coupling' International Journal of Climatology, 34, 3, 655-677, doi:10.1002/joc.3713, (2014).

Roy, I. and Haigh, J. D., Solar cycle signals in sea level pressure and sea surface temperature, Atmos. Chem. Phys., 10, 6, 3147-3153, (2010).

Roy, I. and Haigh, J.D., 'The influence of solar variability and the quasi-biennial oscillation on lower atmospheric temperatures and sea level pressure', Atmospheric Chemistry and Physics (ACP), 11, 11679-11687, ISSN:1680-7316. doi: 10.5194/acp-11-11679-2011, (2011).

Roy, I. and Haigh, J.D. Solar Cycle Signals in the Pacific and the Issue of Timings. Journal of Atmospheric Science, 69, 4, 1446-1451, doi: http://dx.doi.org/10.1175/JAS-D-11-0277.1, (2012).

Roy, I, T. Asikainen, V. Maliniemi, K. Mursula, 'Comparing the influence of sunspot activity and geomagnetic activity on winter surface climate', Journal of Atmospheric and SolarTerrestrial Physics; doi:10.1016/j.jastp.2016.04.009, (2016).

Roy, I. The Role of Natural Factors on Major Climate Variability in Northern Winter. Preprints, 2016080025 (doi: 10.20944/preprints201608.0025.v1 (2016).

Sassi, F. et al., Effect of El Nino-Southern Oscillation on the dynamical, thermal, and chemical structure of the middle atmosphere, J. Geophys. Res., 109, D17108, (2004).

Sato, M., Hansen, J. E., McCormick, M. P. and Pollack, J. B., Stratospheric aerosol optical depths (1850 - 1990), J. Geophys. Res., 98, 22, 987-22, 994, (1993). 
Schneider DP, Okumura Y, Deser C, Observed Antarctic interannual climate variability and tropical linkages. J Climate. 25:4048-4066. doi:10.1175/JCLI-D-11-00273.1, (2012).

Smith, T.M. and Reynolds, R. M., Improved extended reconstruction of SST (1854-1997). J. Climate, 17, 2466-2477, (2004).

Song H-J, Choi E, Lim G-H, Kim YH, Kug J-S, Yeh S-W, The central Pacific as the export region of the EI Niñ-Southern oscillation sea surface temperature anomaly to Antarctic sea ice. J Geophys Res 116:D21112. doi:10.1029/2011JD015645, (2011).

Taguchi, M. and Hartmann, D.L., Increased occurrence of stratospheric sudden warmings during El Nino as simulated by WACCM, J. Clim., 19, 324-332, (2006).

Taschetto AS, England MH., El Nino Modoki impacts on Australian rainfall. Journal of Climate, 22: 3167-3174, (2009).

Thompson, D.W.J. and Wallace, J. M. Annular modes in the extratropical circulation. Part I: month-to-month variability. J. Clim., 13, 1000-1016, (2000).

Thompson et al., An abrupt drop in Northern Hemisphere sea surface temperature around 1970, Nature, 467, 444-447,(2010).

Trenberth, K.E. and Hoar T. J. The 1990-1995 El Niño-Southern Oscillation Event: Longest on record, Geophysical Research Letters, 23, 57-60, (1996).

Trenberth KE, Caron JM, Stepaniak DP, Worley S., Evolution of El Niño-Southern Oscillation and global atmospheric surface temperatures. Journal of Geophysical Research 107(D8): 4065, DOI: 10.1029/2000JD000298, (2002).

Vecchi, G.A. and Soden, B. J., Global Warming and the Weakening of the Tropical Circulation, J. Climate., 20, 4316-4340, (2007).

Weng H, Behera SK, Yamagata T., Anomalous winter climate conditions in Pacific rim during recent El Niño Modoki and El Niño events. Climate Dynamics 32: 663-674, DOI: 10.1007/s00382-008-0394-6, (2009).

White, W. B., Lean, J, Cayan, D.R., and Dettinger, M.D., Response of global upper ocean temperature to changing solar irradiance, J. Geophys. Res.-Oceans, 102(C2), 3255-3266, (1997). 
Xie F, Li JP, Tian WS, Feng J, Signals of EI Niño Modoki in the tropical tropopause layer and stratosphere. Atm Chem Phys 12:5259. doi:10.5194/acp-12-5259-2012, (2012).

Yeh S, Kug J, Dewitte B, Kwon M, Kirtman B and Jin F, El Niño in a changing climate Nature 461, 511-4, (2009).

Yeo SR and Kin KY, Decadal changes in the Southern Hemisphere sea surface temperature in association with El Niño-Southern Oscillation and Southern Annular Mode. Climate Dynamics, 45, 11, 3227-3242, (2015).

Yim, S Y, Bin Wang, Jian Liu, Zhiwei Wu, A comparison of regional monsoon variability using monsoon indices, Clim Dyn, 2013, DOI 10.1007/s00382-013-1956-9, (2013).

Yu J-Y., and H.-K. Kao, Decadal changes of ENSO persistence barrier in SST and ocean heat content indices: 1958-2001. J. Geophys. Res., 112, D13106, doi:10.1029/ 2006JD007654, (2007).

Yu., J.-Y., H.-Y. Kao and T. Lee, Subtropics-Related Interannual Sea Surface Temperature Variability in the Equatorial Central Pacific. Journal of Climate, 23, 2869-2884, (2010).

Yu., J.-Y. and S. T. Kim, Relationships between Extratropical Sea Level Pressure Variations and the Central-Pacific and Eastern-Pacific Types of ENSO, Journal of Climate, 24, 708-720, (2011).

$\mathrm{Yu}$ and Kim, Identification of Central-Pacific and Eastern-Pacific types of ENSO in CMIP3 models, Geophysical Research Letters, 37, 15, 10.1029/2010GL044082, (2010).

Zhang, Y., Wallace, J. M. and Battisti, D. S., ENSO-like interdecadal variability: 1900-93. J. Climate, 10, 1004-1020, (1997).

Zhang, D. and McPhaden, M. J., Decadal variability of the shallow Pacific meridional overturning circulation: Relation to tropical sea surface temperatures in observations and climate change models. Ocean Modelling, 15, 3-4, 250-273, (2006).

Zhao, M. and Dirmeyer, P., Pattern and trend analysis of temperature in a set of seasonal ensemble simulations. Geophys. Res. Lett., 30, doi: 10.1029/2003GL018579, (2003). 